\title{
Seismic Performance of Hybrid and Non-Hybrid Fiber-Reinforced Concrete Based Beam-Column Joint
}

\author{
Pallab Das*, Satyabrata Choudhury \\ Department of Civil Engineering, National Institute of Technology Silchar, Assam, India
}

Received July 2, 2021; Revised September 6, 2021; Accepted September 26, 2021

\section{Cite This Paper in the following Citation Styles}

(a): [1] Pallab Das, Satyabrata Choudhury, "Seismic Performance of Hybrid and Non-Hybrid Fiber-Reinforced Concrete Based Beam-Column Joint," Civil Engineering and Architecture, Vol. 9, No. 6, pp. 1955-1969, 2021. DOI: 10.13189/cea.2021.090625.

(b): Pallab Das, Satyabrata Choudhury (2021). Seismic Performance of Hybrid and Non-Hybrid Fiber-Reinforced Concrete Based Beam-Column Joint. Civil Engineering and Architecture, 9(6), 1955-1969. DOI: 10.13189/cea.2021.090625.

Copyright $\bigcirc 2021$ by authors, all rights reserved. Authors agree that this article remains permanently open access under the terms of the Creative Commons Attribution License 4.0 International License

\begin{abstract}
Beam-column (BC) joints are the most crucial zones of structures wherein that region, the bond, and normal stresses are comparatively higher. In the present study, the seismic performance of the joint region has been improved with reinforcement with various fibers (polypropylene fiber and steel fiber). Tests are performed with various fiber types in the $\mathrm{BC}$ joints under a $100 \mathrm{kN}$ capacity cyclic actuator. The output attributes considered are load, displacement, degradation in the stiffness, drift angle, and dissipation of energy in the $\mathrm{BC}$ joint. The specimens have also been computationally modeled and analyzed for static cases using ANSYS-v14 software. Static analysis procedure has been used to determine the key parameters like displacement, stress, strain, and forces in structural components due to the loads. Percentages of polypropylene fiber are varied between $0.15-0.50 \%$ and the steel fiber is kept constant at $0.75 \%$, while the control specimen (CS) prepared with only normal concrete of mix M25 grade of concrete with characteristic cube compressive strength of $25 \mathrm{MPa}$ without any fibers. Results indicate that the specimen having $0.25 \%$ polypropylene and $0.75 \%$ steel fiber exhibits better performance under reversed cyclic loading. Further, improvement in $\mathrm{BC}$ joints in terms of strength and ductility has been observed in presence of hybrid fibers.
\end{abstract}

Keywords Beam-Column Joint, Hybrid Fibre, Stiffness, Strength, Displacement

\section{Introduction}

Beam-column (BC) joints have a vital role in the reliability of the structural system of the buildings. Due to this cause, structural systems must be designed with appropriate strength and stiffness to uphold the loads transferred from structural elements [1]. The plastic hinge formation in the columns must be prohibited since the effect will be on the entire structure. Because of the congestion of reinforcement in the critical joint area, the casting of the $\mathrm{BC}$ joint will be tedious. This may result in honeycombing in the concrete. However, those recommendations do not apply to fiber-reinforced concrete. In reinforced concrete structures, diagonal cracking and concrete crushing in the joint area may be forbidden by two means, such as assigning large column sizes and closed-loop closely spaced lateral ties around column main steel bars in the joint area. BC joints are very crucial for force and moment transfer within beams and columns. The stress reversal by moments in beam-column joints may cause the formation of higher joint shear forces in the joint area when subjected to seismic excitations [2]. Due to this reason, $\mathrm{BC}$ joints are to be designed for enough strength and stiffness to ensure overall stability and structural integrity. So the detailing of the beam-column joint region must be provided accurately as per the guidelines of IS-13920: 2016.

Recent earthquakes in different places in various countries have led to the significance of reinforced concrete structures with higher ductility. The main 
challenge with these problems is the trend of concrete, i.e., cracking in both its plastic (early-age) and hardened (long-term) state. Cracks at an early age in the concrete are caused by the inherent stresses caused during the initial curing stage of concrete. The shrinkage that causes long-term cracking in the concrete can affect the integrity of the concrete structure and the overall performance on the capacity of concrete.

The strength and ductility of structures are dependent on accurate reinforcement detailing in $\mathrm{BC}$ joints. The force transfer within the $\mathrm{BC}$ joint may not be proper and accurate if the assigned joint shear strength is not proper. The $\mathrm{BC}$ joint portion is exposed to horizontal and vertical shear forces because of seismic excitations, for which magnitudes are much higher than the adjacent members to beams and columns [3]. The plastic hinge formation in columns must be restricted since it affects the entire structure [4]. Due to the formation of multiple cracks, ordinary concrete loses its tensile resistance. However, fiber-reinforced concrete can withstand a considerable part of the resistance following concrete cracking to accept further load cycles [5-6].

Fiber-Reinforced Polymer (FRP) has significant characteristics, for example, high elasticity, high durability, cracking resistance, light-weight, and imperviousness, to ensure the capacity of concrete for reversal of stresses [7-8]. Concrete structures are designed for sufficient and required capacities to play proficiently during seismic excitation [9]. In current years, the use of rebar-reinforced with hybrid fibers has increased considerably. When there is an increase in the loads applied, human errors in the initial phases of construction, or when a loss of strength for structural members due to deterioration over time, then proper strengthening of the structure is required [10]. The strengthening of the structure is an efficient and economical option since the demolishing and reconstruction of the structure is a very tedious, time dependant, and costly affair. To improve the seismic capacity of reinforced concrete structures, researchers have been experimenting with various alternative materials like basalt, glass, polypropylene, steel, carbon, fiber composite (FRP) [11].

Steel fiber-reinforced concrete may be introduced for the improvement of the strength and ductility characteristics of the $\mathrm{BC}$ joint. Due to high modulus and stiffness, steel fibers are capable of enhancing the compressive strength and durability of concrete [12-13]. On the other side, polypropylene has important characteristics to arrest crack propagation [14]. Hybrid fibers, which are a combination of different fibers have been tested to be the substitute materials for the improvement of strength and ductility of $\mathrm{BC}$ joint [15-16]. Due to the formation of multiple cracks, ordinary concrete loses its tensile resistance. However, fiber-reinforced concrete can withstand a considerable part of its resistance following the cracking of concrete to accept more load cycles applied to the same [17].
The occurrence of diagonal cracking and crushing of concrete in the joint area can be avoided either by assigning large column sizes and by applying closed-loop closely spaced lateral ties around column main steel bars [18]. This bond developed because the same will jointly help keep the concrete in place and help carry shear forces, thereby lowering cracking and the collapse of the concrete. However, the above-said option for improvement of strength of the joint the region is restricted to initial cycles of load, and later on, it may trail the specimen cracking and crushing near the joint on further cycles of load [19]. So in the present approach, an effort has been made to improve the strength of the joint region by using the ductile approach and the replacement of ordinary concrete being used in general construction practices with fiber reinforced concrete.

The introduction of closed-loop closely spaced lateral ties and evenly dispersed fibers to concrete would help to resist crack and subsequent improvement of its properties. Various fibers used in concrete are namely steel, polypropylene, glass, carbon, and nylon. This type of concrete with the addition of fibers is known as Fiber Reinforced Concrete. In this composite object, short discrete fibers are distributed randomly throughout the mass of concrete [20]. The overall efficiency of this composite material is comparatively superior to that of normal concrete, and many other materials used in construction have similar costs [21-22]. On the other hand, synthetic fibers like carbon, glass, aramid, and natural fibers such as Jute, sisal, coir, flax, cotton, pineapple, etc., have immense reinforcement capacities combined with polymers. Being cheaper and having good inference of specific quality and specific modulus, these materials are very reliable. However, synthetic fibers are gradually getting replaced for their impact on the environment, leading us to the revolution of engineering materials [23].

Recently, Attari et al. [24] have performed an experimental investigation to evaluate the strength of fiber-reinforced polymer-based reinforced concrete beam-column joints. The tests are conducted with reverse cyclic loading under constant axial load. Generation of strain and cracking fields are observed both numerically and experimentally. Saghafi et al. [25] have experimentally examined the ductility ratio, energy dissipation, and the cyclic behavior of the frames made up of fiber-reinforced cementitious composites. Results indicate that the lateral behavior has been significantly improved, including various seismic parameters.

Pertinent literature reveals that recently many research works have been ongoing to look into the response of reinforced concrete structures under-stimulated seismic conditions. In general, the lack of accessible scientific know-how in the area of earthquake engineering and the need for proper design recommendations and practices has encouraged these research programs [26-27]. Numerous reinforced concrete buildings that have suffered severe 
damage in the recent past were of conventional design. Considering these factors, capacity enhancement of the $\mathrm{BC}$ joint area has been attempted by using supplementary reinforcement using a variety of combinations of fibers. Seven beam-column joint specimens are considered for this study. The rebar detailing for the specimens is done according to the provisions prescribed in IS-13920: 2016 [28]. In this study, the properties of the $\mathrm{BC}$ joint are examined in terms of parameters such as load, displacement, stiffness degradation, drift angle, and dissipation of energy by the $\mathrm{BC}$ joint, considering various fiber combinations in the test specimens. The fibers used in this study are steel fiber and polypropylene fiber. Combinations of the fibers that have been used in the test specimen are polypropylene fiber $(0.15-0.50 \%)$, steel fiber $(0.75 \%)$, and the control specimen prepared from a normal concrete mix of M25 grade of concrete. The behavior of the test specimens with various types of fibers is examined, and the specimen giving reliable performance under reverse cyclic load is identified. It has been observed from the tests that the application of hybrid fibers would be helpful in the improvement of the strength and ductility of the $\mathrm{BC}$ joints.

\section{Numerical Analysis}

To evaluate the range of load and strain energy that can be sustained by the specimens is being preliminary observed by the computational analysis. The ANSYS-v14 software program used in the present case is a general-purpose FE Analysis package for solving plenty of engineering problems numerically. Appropriate element type selection is the key criterion for finite element analysis. For $\mathrm{BC}$ joints, the modeling of concrete is done by using special elements available in the package i.e. SOLID65 element, and similarly, reinforcement is modeled by using the LINK180 element. The study has been carried out to simulate the behavior of these joints subjected to monotonic loading. Nonlinear static analysis has been carried out for getting prior information about the load at first crack, crack pattern, load, and deflection at yielding, ultimate load, etc. for all the specimens in order to appropriately plan the arrangement of experimental investigation. In the numerical study, concrete has been modeled using a 3-D solid element (SOLID65), which is accomplished by incorporating cracking as well as crushing besides plastic and creep behavior. An iterative solution has been performed as the adapted element has the non-linear characteristics.

The characteristic cube compressive strength of the concrete $\left(f_{c k}\right)$ is $25.0 \mathrm{MPa}$, the tensile strength of the concrete $\left(f_{r}\right)$ is $3.5 \mathrm{MPa}$, and the modulus of elasticity (Es) is $25000 \mathrm{MPa}$ has been used as material properties. The reinforcement steel was modeled with a series of two-node link elements (LINK 180). The properties pertaining to the link included an initial yield stress of $500 \mathrm{MPa}$. The boundary conditions were simulated with the precision in the test set-up of the horizontal and vertical restraints, representing a pin connection applied at the top and bottom of the column. The displacement at the free end of the column was applied using a slowly increasing monotonic method. The mesh size was fixed at $25 \mathrm{~mm}$. Since in reality, a full fixity at both ends of the columns could not be attained, a series of horizontal and vertical springs were used to model the lateral stiffness of both the end clamping mechanisms of the test setup. In the present study, the displacement on the both the ends of the column in the two directions were set to zero (both ends of the columns were hinged).

A static analysis of the $\mathrm{BC}$ joint is done with the application of a static load of $10 \mathrm{kN}$. The static load is applied to the beam tip at the same point as that of the experimental specimen. Both the ends of the column were kept constrained along with all the three directions $\mathrm{X}, \mathrm{Y}$, and $\mathrm{Z}$, and the load is applied along the direction of the column length. A standard earth gravity load is applied to the column. The properties for each specimen were applied after experimentally calculating their material properties in the lab namely the compressive strength of cubes and splitting tensile strength of cylinders. The energy dissipated for each specimen has been obtained.

In this study, seven BC joint specimens are modeled in a one-third scale. The rebar detailing for the specimens is done in compliance with the provisions prescribed in IS-13920: 2016. Analysis results for two specimens are presented in Fig. 1(a) and Fig. 1(b) for specimen CS and HFRC2 respectively for comparison only. From the results obtained in ANSYS, it has been studied that the strain energy is a maximum for a specimen with hybrid fibers with $0.75 \%$ steel and $0.25 \%$ polypropylene which was withstanding with high energy dissipation. 


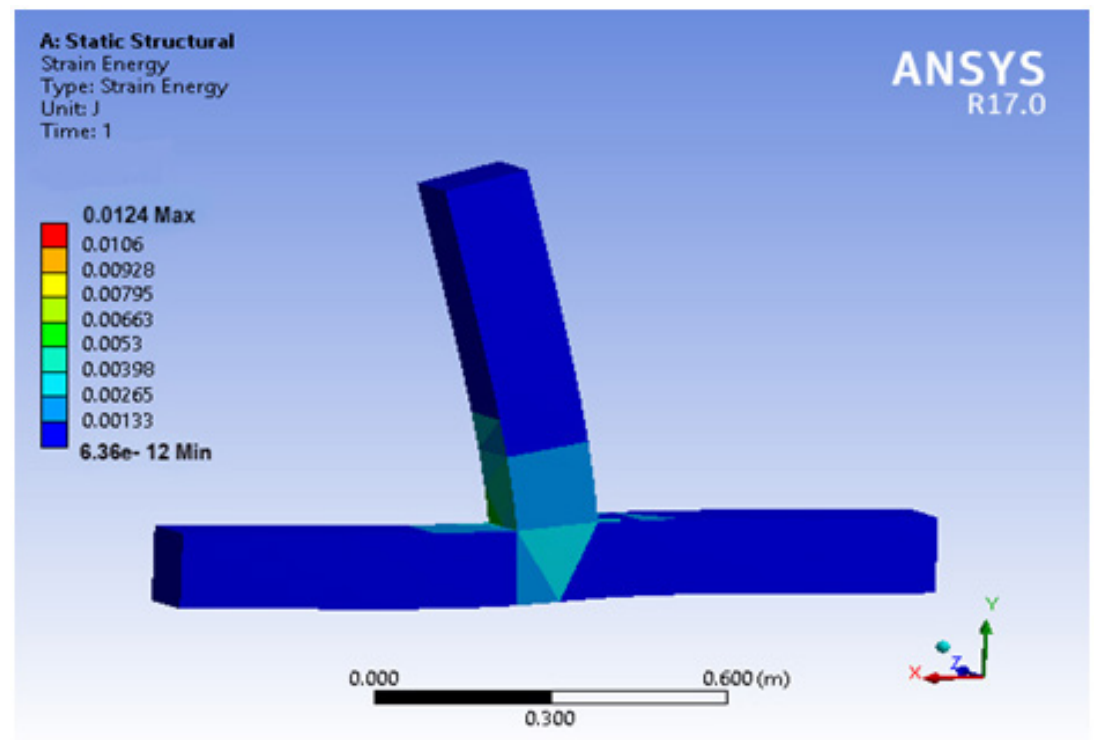

Figure 1(a). Strain energy of control specimen.

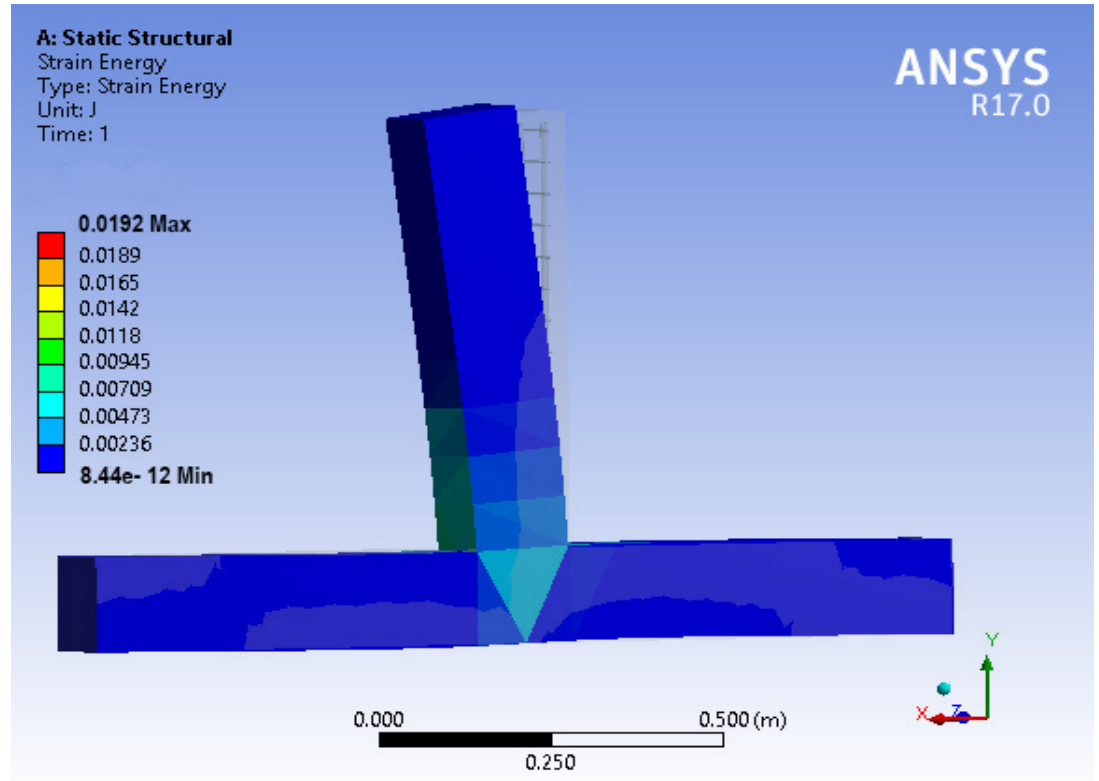

Figure 1(b). Strain energy of specimen HFRC2

\section{Experimental Programme}

Experimental studies were carried out to identify and compare the behavior of the joint specimens with combinations of various fibers. The experimental models used were of one-third scale of actual joints. All the specimens were cast with concrete of specified characteristic cube strength of $25 \mathrm{MPa}$ and they had a common cross-sectional dimension of $120 \times 150 \mathrm{~mm}$ for both the beam and column. The beam length from the face of the column is $690 \mathrm{~mm}$ and the total length of the column is $1400 \mathrm{~mm}$. The characteristic cube compressive strength of the concrete (fck) is $25.0 \mathrm{MPa}$, the tensile strength of the concrete (fr) is $3.5 \mathrm{MPa}$, and the modulus of elasticity (Es) is $25000 \mathrm{MPa}$ which has been achieved after testing set of at least 30 cubes for which standard deviation has been calculated as 1.67. The tensile strength of steel has been tested and found to be $592 \mathrm{MPa}$ and the modulus of elasticity is $2 \times 10^{5} \mathrm{MPa}$. In this study, seven beam-column joint specimens are prepared in one-third scale for which rebar detailing is done in compliance with the provisions prescribed in IS-13920: 2016. The overall dimensions and reinforcement detailing of the test specimens are shown in Fig. 2(a) and also tabulated in Table 1. The beam-column joint specimens cast are control specimen, polypropylene fiber $(0.15-0.50 \%)$, steel fiber $(0.75 \%)$ specimen as mentioned in Table 2. The specimens of beam-column joints have been tested in servo-controlled hydraulic actuator of the capacity of $100 \mathrm{kN}$. 


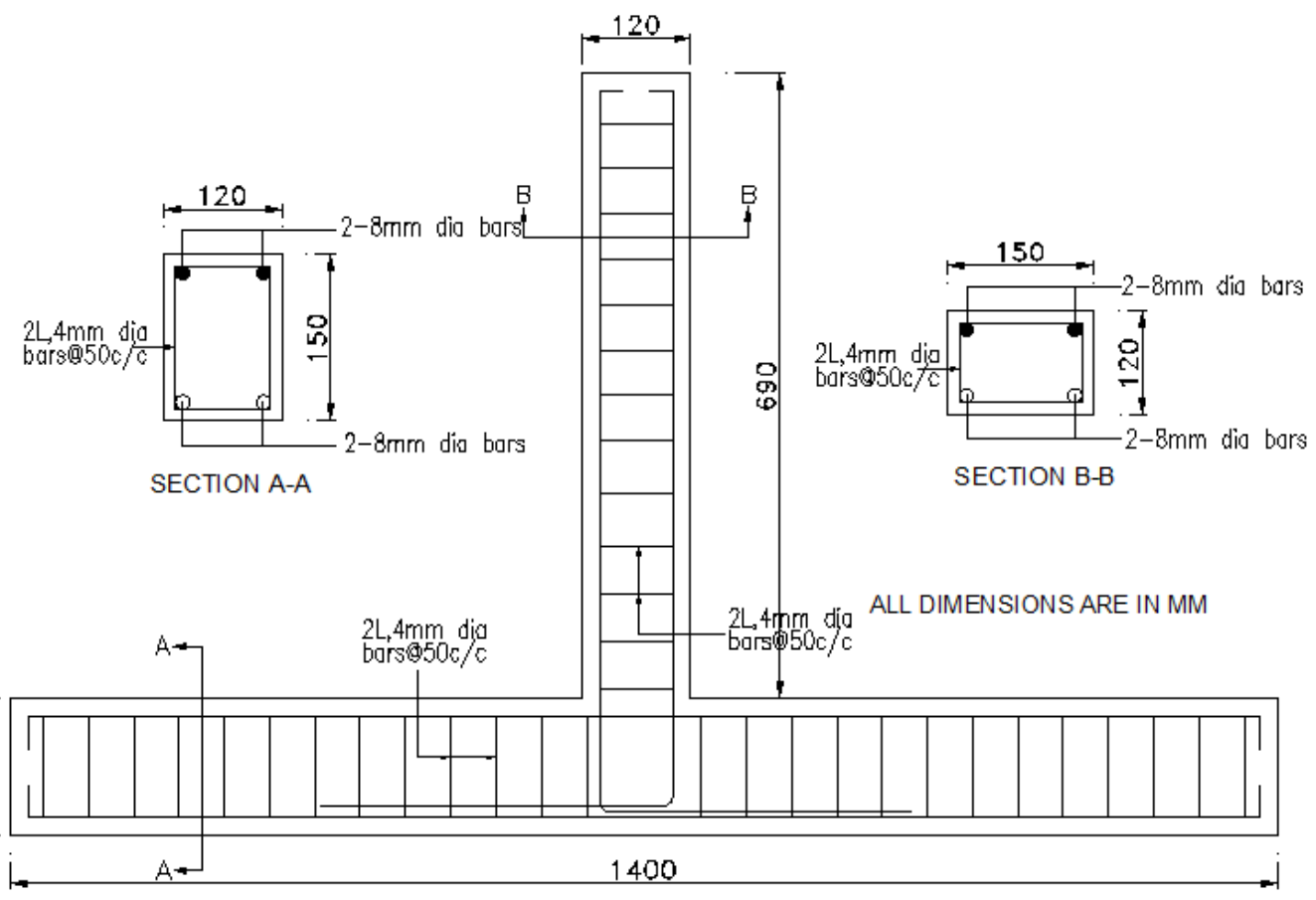

Figure 2(a). Test specimen details

Table 1. Reinforcement details used in the specimens

\begin{tabular}{ccccccc}
\hline Specimen & \multicolumn{3}{c}{ Beams } & \multicolumn{2}{c}{ Column } \\
\cline { 2 - 7 } & $\begin{array}{c}\text { Effective } \\
\text { Span }(\mathbf{m m})\end{array}$ & $\begin{array}{c}\text { Cross } \\
\text { Section } \\
(\mathbf{m m})\end{array}$ & $\begin{array}{c}\text { Main Steel } \\
\text { Bars }\end{array}$ & $\begin{array}{c}\text { Effective Span } \\
(\mathbf{m m})\end{array}$ & $\begin{array}{c}\text { Cross } \\
\text { Section } \\
(\boldsymbol{m m})\end{array}$ & $\begin{array}{c}\text { Main Steel } \\
\text { Bars }\end{array}$ \\
\hline CS & 615 & $120 \times 150$ & $4 \# 8 \varnothing$ & 1300 & $120 \times 150$ & $4 \# 8 \varnothing$ \\
PFRC1 & 615 & $120 \times 150$ & $4 \# 8 \varnothing$ & 1300 & $120 \times 150$ & $4 \# 8 \varnothing$ \\
PFRC2 & 615 & $120 \times 150$ & $4 \# 8 \varnothing$ & 1300 & $120 \times 150$ & $4 \# 8 \varnothing$ \\
SFRC & 615 & $120 \times 150$ & $4 \# 8 \varnothing$ & 1300 & $120 \times 150$ & $4 \# 8 \varnothing$ \\
HFRC1 & 615 & $120 \times 150$ & $4 \# 8 \varnothing$ & 1300 & $120 \times 150$ & $4 \# 8 \varnothing$ \\
HFRC2 & 615 & $120 \times 150$ & $4 \# 8 \varnothing$ & 1300 & $120 \times 150$ & $4 \# 8 \varnothing$ \\
HFRC3 & 615 & $120 \times 150$ & $4 \# 8 \varnothing$ & 1300 & $120 \times 150$ & $4 \# 8 \varnothing$ \\
\hline
\end{tabular}

Table 2. Specimen details prepared for tests

\begin{tabular}{cccc}
\hline \multirow{2}{*}{ Sl. No. } & Designation of Specimens & \multicolumn{2}{c}{ Volume fraction of fibre (\%) } \\
\cline { 3 - 4 } & & Steel & Polypropylene \\
\hline 1 & PFRC1 & 0 & 0 \\
2 & PFRC2 & 0 & 0.15 \\
3 & SFRC & 0 & 0.25 \\
4 & HFRC1 & 0.75 & 0 \\
5 & HFRC2 & 0.75 & 0.15 \\
6 & HFRC3 & 0.75 & 0.25 \\
7 & & 0.75 & 0.50 \\
\hline
\end{tabular}

\section{Results and Discussions}

The specimens were tested in the cyclic actuator test setup as shown in Fig. 2(b). The loading mechanism is as explained above and the loading history is shown in Fig. 3.
Fig. 4 and Fig. 5 show the pictures of the joint area of the specimen after completion of the experiment for specimen CS and HFRC2 respectively. The hysteretic response for all the specimens obtained by plotting the test data is shown in Fig 6a-6g. 


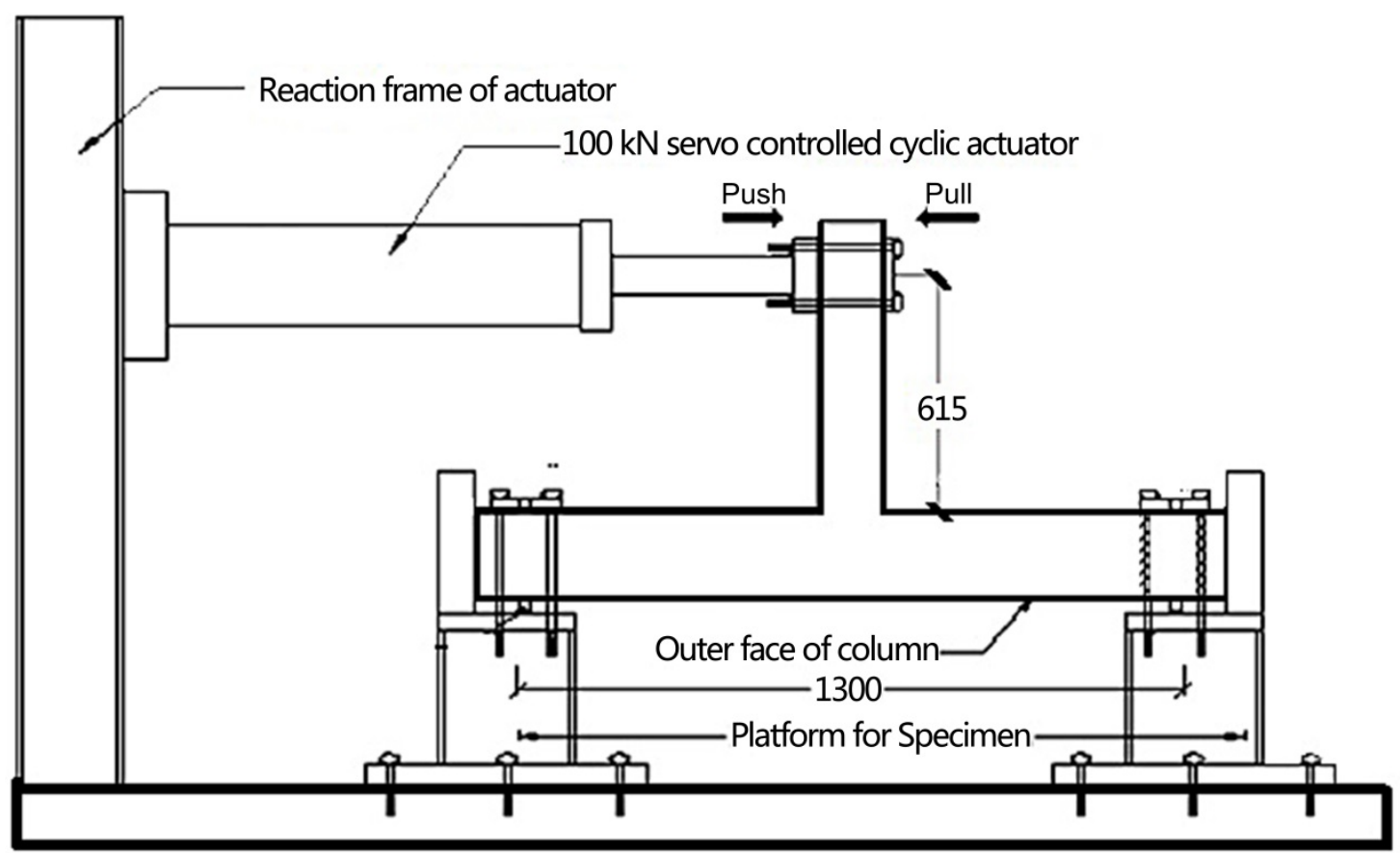

Figure 2(b). Set-up of Cyclic Actuator
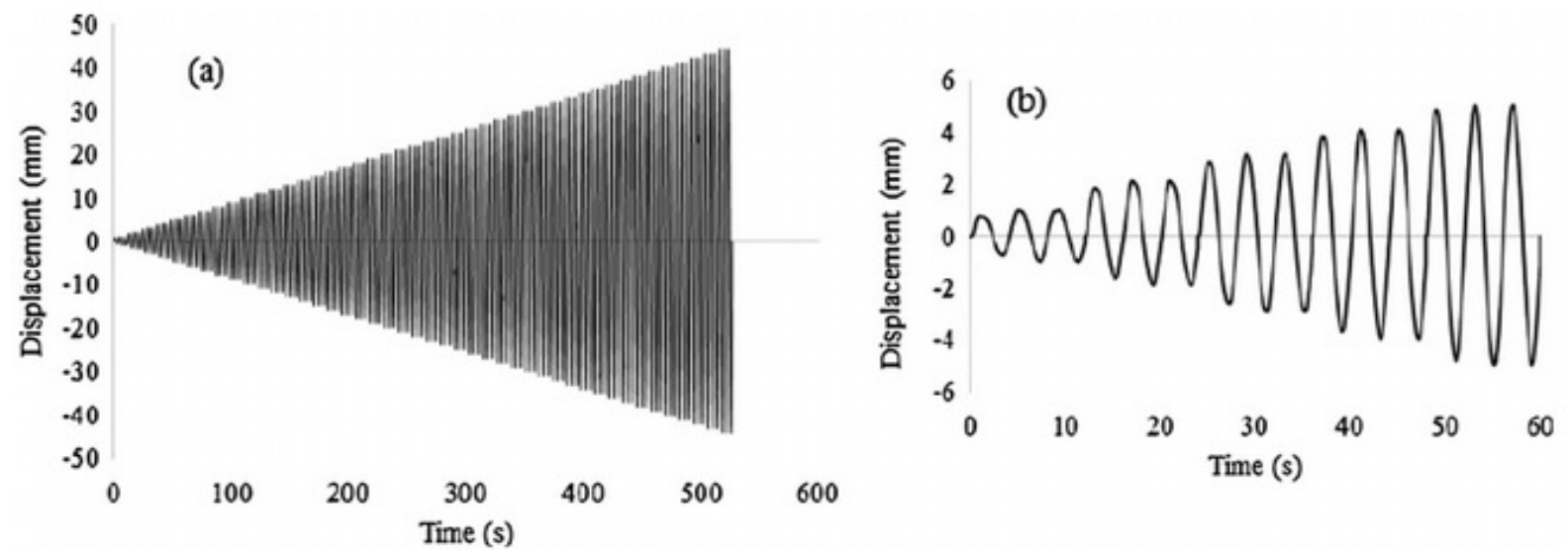

Figure 3. Applied specimen loading history

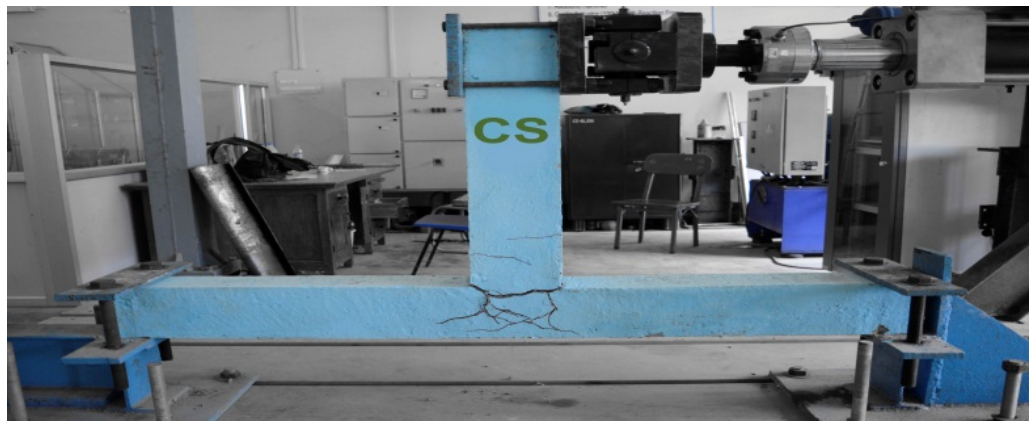

Figure 4. Crack Pattern for Control Specimen (CS) 


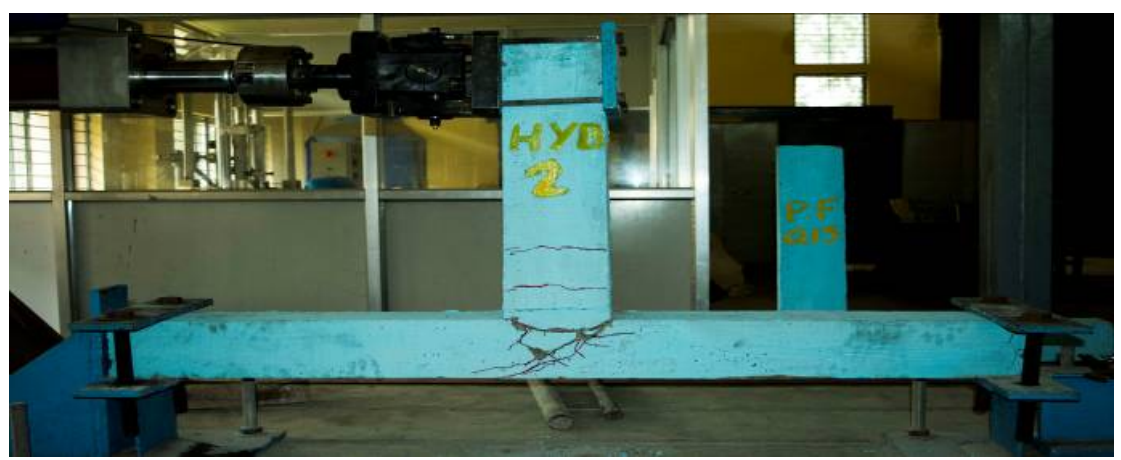

Figure 5. Crack pattern for HFRC2 specimen

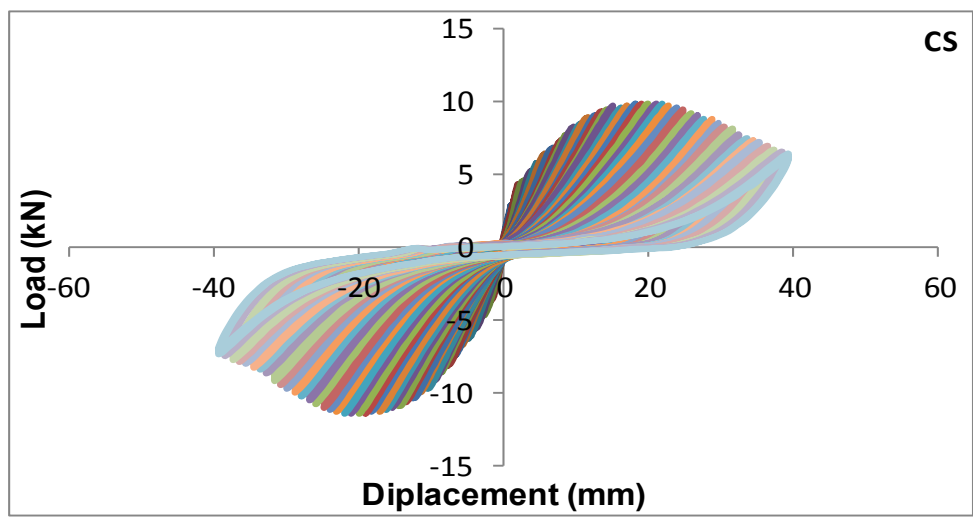

Figure 6(a). Hysteresis Curve of CS specimen

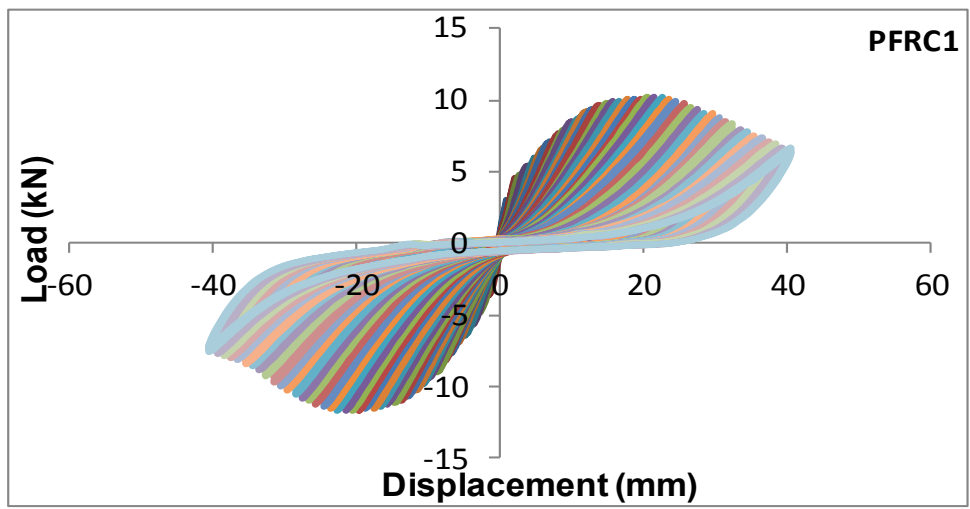

Figure 6(b). Hysteresis curve for PFRC1 specimen

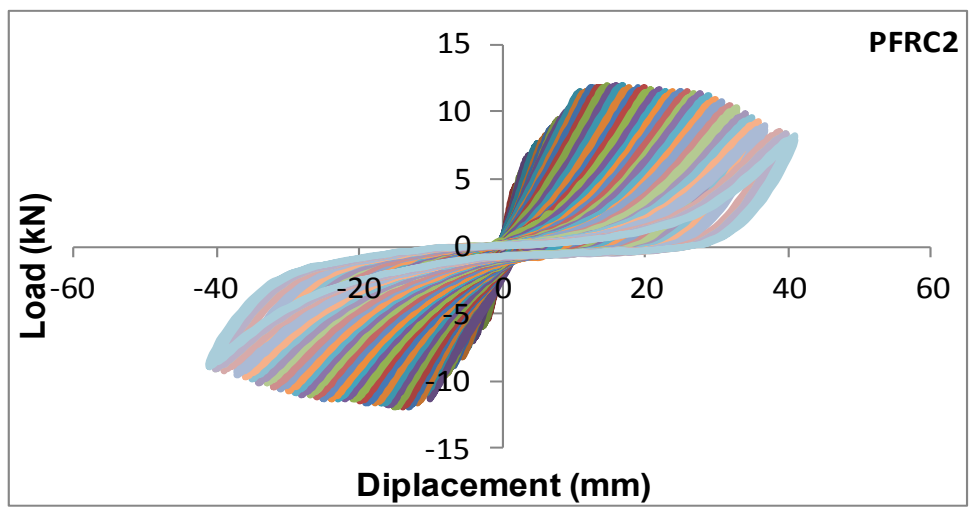

Figure 6(c). Hysteresis curve for PFRC2 specimen 


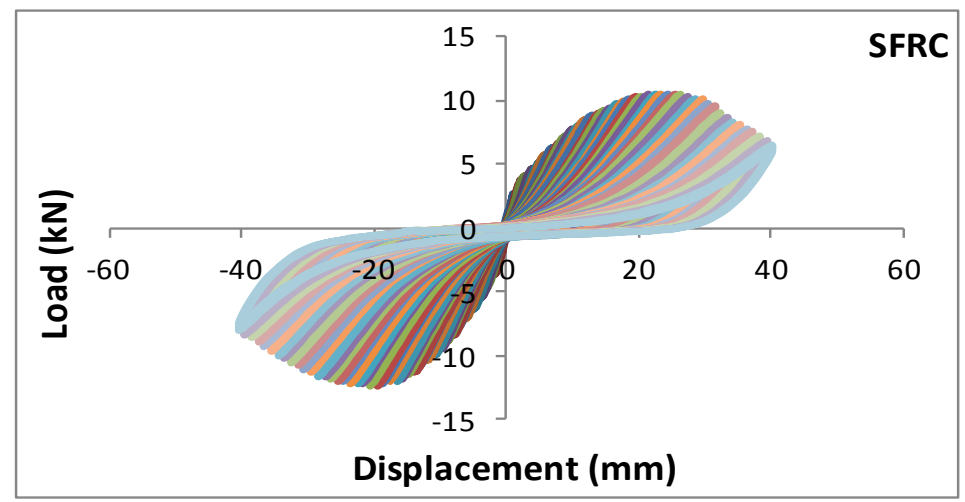

Figure 6(d). Hysteresis loop for SFRC specimen

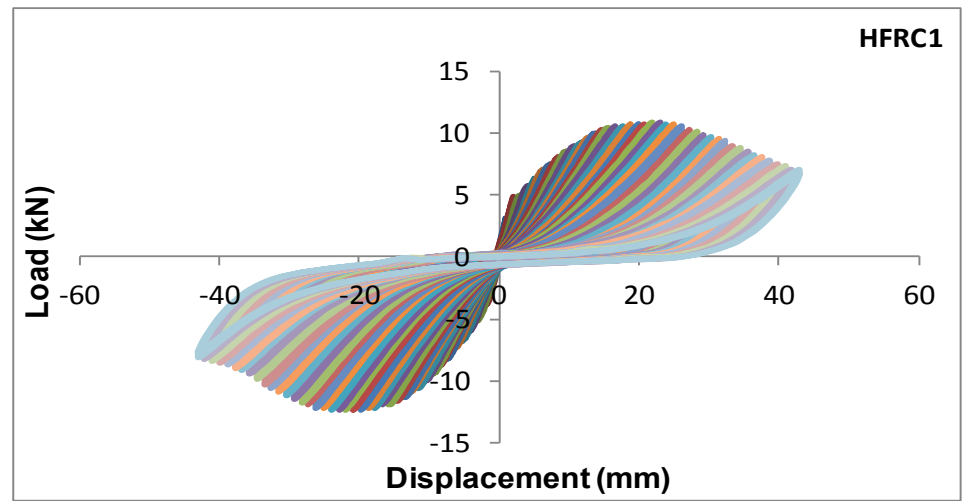

Figure 6(e). Hysteresis curve for HFRC1 specimen

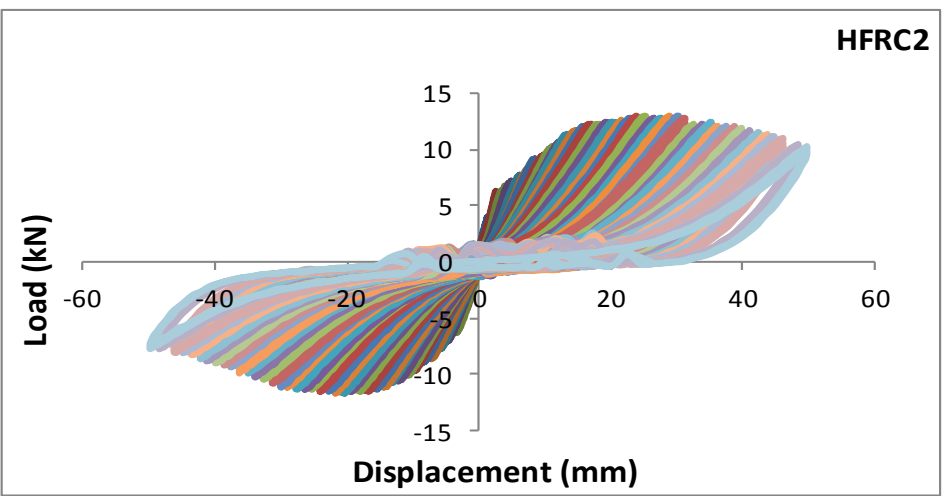

Figure 6(f). Hysteresis curve for HFRC2 specimen

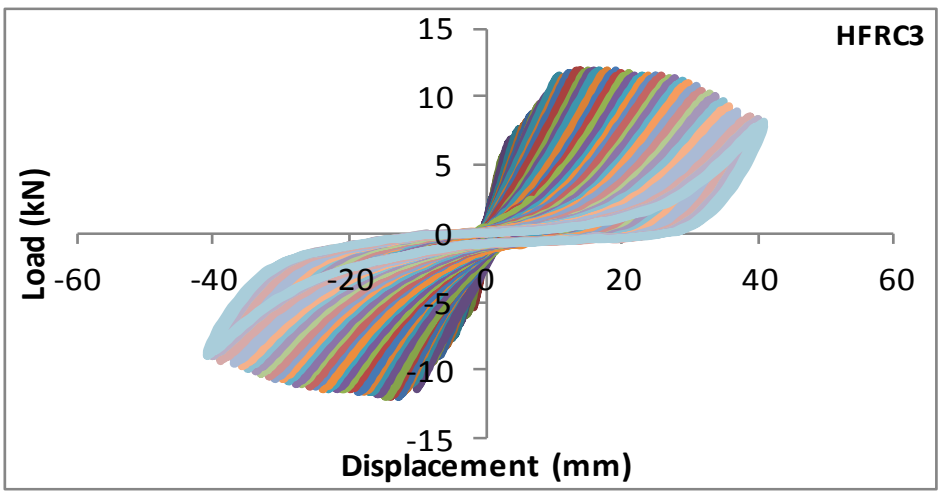

Figure 6(g). Hysteresis curve for HFRC3 specimen 


\subsection{Hysteresis Behavior}

For the control specimen (CS); the occurrence of the flexural cracks in the joint region took place at displacement amplitude of $\pm 1 \mathrm{~mm}$. Further cracks appeared in the joint and the beam areas thereafter as displacement amplitude has been increased. It is observed from the hysteresis loop that the specimen attains the maximum load of $10.56 \mathrm{kN}$ in the push direction at $20^{\text {th }}$ cycle at a displacement of $20 \mathrm{~mm}$. Similarly, a maximum load of 9.49 $\mathrm{kN}$ in the pull direction is observed at $17^{\text {th }}$ cycle at a displacement of $17 \mathrm{~mm}$. At higher displacement amplitudes, cracks in the beam-column interface were observed and the previous cracks in the joint region become more extensive. Spalling of concrete was observed at upper and lower columns near the joint panel. The experiment was stopped at displacement amplitude of $\pm 41 \mathrm{~mm}$ at which load came down to the desired level. Ultimate load carrying capacity of the specimen was recorded to be $10.025 \mathrm{kN}$.

The specimen PFRC1 was tested in the cyclic actuator test setup. The hysteresis response obtained by plotting the test data is shown in Fig. 6(b) for the PFRC1, the occurrence of the flexural cracks in the joint region took place at displacement amplitude of $\pm 2 \mathrm{~mm}$. Additional cracks appeared in the joint and the beam areas thereafter as displacement amplitude has been increased. It is observed from the hysteresis loop that the specimen attains the maximum load of $10.91 \mathrm{kN}$ at $20^{\text {th }}$ cycle at a value of displacement of $20 \mathrm{~mm}$ in the direction of the push. Similarly, the maximum load of $9.75 \mathrm{kN}$ is observed at $13^{\text {nd }}$ cycle at a value of displacement of $13 \mathrm{~mm}$ in the direction of pull. At higher displacement amplitudes, cracks in the interface of beam-column were observed and the previous cracks in the joint region became more extensive. Spalling of concrete was observed at upper and lower columns near the joint panel. The experiment ended at displacement amplitude of $\pm 41 \mathrm{~mm}$ at which load came down to the desired level. A load of $10.33 \mathrm{kN}$ has been recorded for the specimens before failure which indicates the ultimate load-carrying capacity of the specimen.

The hysteresis response obtained by plotting the test data is shown in Fig. 6(c) for the specimen PFRC2, the occurrence of the flexural cracks in the joint region took place at displacement amplitude of $\pm 2 \mathrm{~mm}$. Additional cracks appeared in the joint and the beam areas thereafter as displacement amplitude has been increased. It is observed from the hysteresis loop that the specimen attains the maximum load of $11.99 \mathrm{kN}$ at the $17^{\text {th }}$ cycle at a value of displacement of $19 \mathrm{~mm}$ in the direction of the push. Similarly, the maximum load of $11.98 \mathrm{kN}$ has been noticed at $15^{\text {th }}$ cycle at a displacement of $15 \mathrm{~mm}$ in the direction of pull. At higher displacement amplitudes, cracks in the interface of beam-column were observed and the previous cracks in the joint region became more extensive. Spalling of concrete was observed at upper and lower columns near the joint panel. The experiment was ended at displacement amplitude of $\pm 41 \mathrm{~mm}$ at which load came down to the desired level. A load of $11.99 \mathrm{kN}$ has been recorded for the specimens before failure which indicates its ultimate load-carrying capacity of the specimen.

For specimen SFRC, the occurrence of the flexural cracks in the joint region took place at displacement amplitude of $\pm 2 \mathrm{~mm}$. Additional cracks appeared in the joint and the beam areas thereafter as displacement amplitude has been increased. It is observed from the hysteresis loop that the specimen attains the maximum load of $10.46 \mathrm{kN}$ at $23^{\text {rd }}$ cycle at a value of displacement of $23 \mathrm{~mm}$ in the direction of push which is shown in Fig. 6(d). Similarly, the maximum load of $12.35 \mathrm{kN}$ has been noticed at the $20^{\text {th }}$ cycle at a value of displacement of $20 \mathrm{~mm}$ in the direction of pull. At higher displacement amplitudes, cracks in the interface of beam-column were observed and the previous cracks in the joint region became more extensive. Although, the widening of diagonal cracks was considerably prevented in the joint region due to the presence of steel fibers in the region. Spalling of concrete was observed at upper and lower columns near the joint panel. The experiment was ended at displacement amplitude of \pm $42 \mathrm{~mm}$ at which load came down to the desired level. A load of $11.40 \mathrm{kN}$ has been recorded for the specimens before failure which indicates the ultimate load-carrying capacity of the specimen.

It is observed from the hysteresis loop that the specimen HFRC1 attains the maximum load of $11.44 \mathrm{kN}$ at the $21^{\text {st }}$ cycle at a value of displacement of $21 \mathrm{~mm}$ in the direction of push which is shown in Fig. 6(e). Similarly, the maximum load of $13.15 \mathrm{kN}$ has been noticed at the $22^{\text {nd }}$ cycle at a value of displacement of $22 \mathrm{~mm}$ in the direction of pull. At higher displacement amplitudes, cracks in the interface of beam-column were observed and the previous cracks in the joint region became more extensive. Spalling of concrete was observed at upper and lower columns near the joint panel. The experiment ended at displacement amplitude of $\pm 43 \mathrm{~mm}$ at which load came down to the desired level. A load of $12.30 \mathrm{kN}$ has been recorded for the specimens before failure which indicates the ultimate load-carrying capacity of the specimen.

It is observed from the hysteresis loop that the specimen HFRC2 attains the maximum load of $12.06 \mathrm{kN}$ at the $19^{\text {th }}$ cycle at a value of displacement of $19 \mathrm{~mm}$ in the direction of push which is shown in Fig. 6(f). Similarly, the maximum load of $13.19 \mathrm{kN}$ has been noticed at the $23^{\text {rd }}$ cycle at a value of displacement of $23 \mathrm{~mm}$ in the direction of pull. At higher displacement amplitudes, cracks in the interface of beam-column were observed and the previous cracks in the joint region became more extensive. Spalling of concrete was observed at upper and lower columns near the joint panel. The experiment ended at displacement amplitude of $\pm 43 \mathrm{~mm}$ at which load came down to the desired level. A load of $12.63 \mathrm{kN}$ has been recorded for the specimens before failure which indicates its ultimate load-carrying capacity of the specimen

It is observed from the hysteresis loop that the specimen 
HFRC1 attains the maximum load of $11.44 \mathrm{kN}$ in the direction of push at $21^{\text {st }}$ cycle at a value of displacement of $21 \mathrm{~mm}$. Similarly, the maximum load of $13.15 \mathrm{kN}$ in the direction of pull has been noticed at $22^{\text {nd }}$ cycle at a value of displacement of $22 \mathrm{~mm}$. At higher displacement amplitudes, cracks in the beam-column interface were observed and the previous cracks in the joint region became more extensive. Spalling of concrete was observed at upper and lower columns near the joint panel. The experiment was stopped at displacement amplitude of $\pm 43 \mathrm{~mm}$ at which load came down to the desired level. Ultimate load carrying capacity of the specimen was found to be $12.3 \mathrm{kN}$.

It is observed from the hysteresis loop that the specimen HFRC 3 attains the maximum load of $12.14 \mathrm{kN}$ at $21^{\text {st }}$ cycle at a value of displacement of $21 \mathrm{~mm}$ in the direction of push which is shown in Fig. 6(g). Similarly, the maximum load of $12.46 \mathrm{kN}$ is observed at the $22^{\text {nd }}$ cycle at a displacement of $22 \mathrm{~mm}$ in the direction of pull. At higher displacement amplitudes, cracks in the interface of beam-column have been noticed and the previous cracks in the joint region became more extensive. Spalling of concrete was observed at upper and lower columns near the joint panel. The experiment was ended at displacement amplitude of \pm $43 \mathrm{~mm}$ at which load came down to the desired level. A load of $12.30 \mathrm{kN}$ has been recorded for the specimens before failure which indicates the ultimate load-carrying the capacity of the specimen.

The load-deflection characteristics for all the test specimens are shown in Fig. 7 and are also tabulated in Table 3. From the test results of all the specimens tested, it can be noticed that the HFRC2 specimen has been exposed to a maximum peak load of $13.19 \mathrm{kN}$ in the backward cycle and the specimen HFRC 3 has been exposed to a maximum load of $12.14 \mathrm{kN}$ in the forward cycle. Further, it has been observed that the maximum average peak load is encountered by the HFRC2 specimen. This result represents that the HFRC2 specimen is suitable for maximum load-carrying capacity

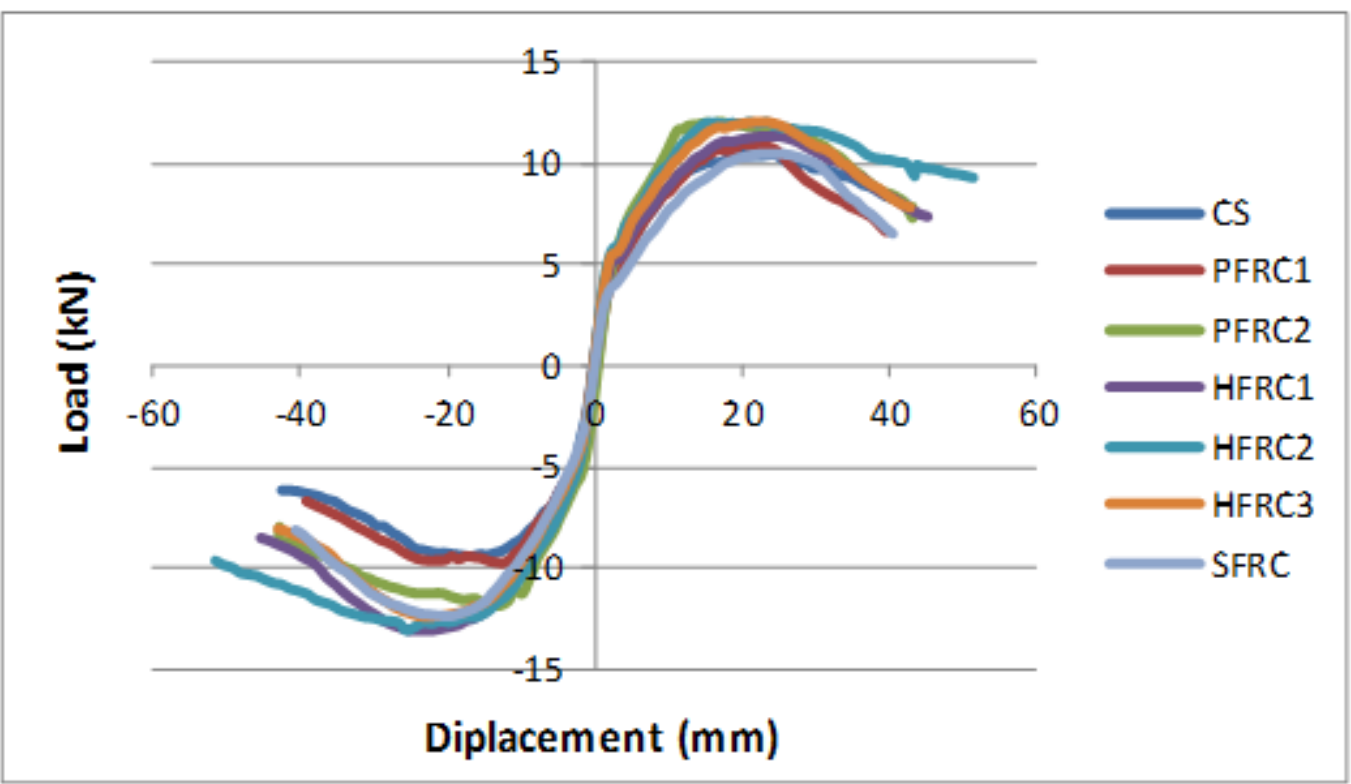

Figure 7. Comparison of load vs. deflection

Table 3. Test Results

\begin{tabular}{|c|c|c|c|c|c|}
\hline \multirow[t]{2}{*}{$\begin{array}{l}\text { Designation of } \\
\text { specimen }\end{array}$} & \multirow[t]{2}{*}{$\begin{array}{c}\text { First crack load } \\
(\mathrm{kN})\end{array}$} & \multicolumn{2}{|c|}{$\begin{array}{c}\text { Ultimate load } \\
(\mathbf{k N})\end{array}$} & \multicolumn{2}{|c|}{$\begin{array}{l}\text { Deflection at ultimate load } \\
\qquad(\mathrm{mm})\end{array}$} \\
\hline & & Forward cycle & Reverse cycle & Forward cycle & Reverse cycle \\
\hline $\mathrm{CS}$ & 3.15 & 10.56 & 9.49 & 20 & 17 \\
\hline PFRC1 & 2.72 & 10.91 & 9.75 & 20 & 13 \\
\hline PFRC2 & 3.28 & 11.99 & 11.98 & 17 & 15 \\
\hline SFRC & 3.31 & 12.35 & 12.35 & 23 & 20 \\
\hline HFRC1 & 3.42 & 13.15 & 13.15 & 21 & 22 \\
\hline HFRC2 & 4.03 & 13.19 & 13.19 & 19 & 23 \\
\hline HFRC3 & 3.51 & 12.46 & 12.46 & 21 & 22 \\
\hline
\end{tabular}


Table 4. Energy absorption capacity and displacement ductility

\begin{tabular}{|c|c|c|c|c|c|}
\hline \multirow[t]{2}{*}{$\begin{array}{c}\text { Designation of } \\
\text { specimen }\end{array}$} & \multirow[t]{2}{*}{$\begin{array}{l}\text { Energy absorption } \\
\text { capacity }(\mathrm{kN}-\mathrm{mm})\end{array}$} & \multirow[t]{2}{*}{$\delta_{y}(m m)$} & \multirow[t]{2}{*}{$\delta_{\mathrm{u}}(\mathrm{mm})$} & \multicolumn{2}{|c|}{$\begin{array}{c}\text { Displacement ductility } \\
\text { factor, } \psi\end{array}$} \\
\hline & & & & Absolute & Relative \\
\hline CS & 6852.39 & 7.82 & 33.92 & 4.33 & 1.00 \\
\hline PFRC1 & 7215.65 & 5.26 & 34.42 & 6.54 & 1.51 \\
\hline PFRC2 & 7684.67 & 8.22 & 36.45 & 4.43 & 1.02 \\
\hline SFRC & 8200.34 & 5.71 & 40.93 & 7.16 & 1.65 \\
\hline HFRC1 & 9523.48 & 4.57 & 43.87 & 9.61 & 2.21 \\
\hline HFRC2 & 11186.80 & 4.75 & 53.15 & 11.18 & 2.58 \\
\hline HFRC3 & 10623.72 & 4.40 & 40.93 & 9.30 & 2.14 \\
\hline
\end{tabular}

\subsection{Energy Absorption and Displacement Ductility}

The area under the load-deflection curve represents the capacity of energy absorption. The capacity for energy absorption has been calculated and the obtained values are tabulated in Table 4. From the results it can be observed that there is a consistent gain in energy absorption capacity and maximum value has been noticed for HFRC2 specimen with $0.75 \%$ steel fibers and $0.25 \%$ polypropylene fibers, which is found to be approximately 1.63 times higher than that of CS specimens. In the elastic range, the seismic-resistant structure is required to be capable of behaving in a more ductile way when being exposed to several cycles of seismic loads. Ductility is the ability of the material to undergo significant plastic deformation before failure. The ductility factor which is an indicator of ductility of a material and is defined as the ratio of maximum displacement $\left(\delta_{u}\right)$ at the failure to the yield displacement $\left(\delta_{y}\right)$. The ductility factors calculated have been tabulated in Table 4 .

\subsection{Cumulative Energy and Drift Angle (\%)}

The seismic-resistant structures should be capable of dissipating a higher amount of energy. They should be able to resist the strong ground motion of earthquakes due to the ability to dissipate seismic energy. The ductility of the joint region of the specimens has a great role in energy dissipation and is created mainly by inelastic deformations of the BC specimens. The same can be calculated from the area within the hysteresis loop of the load-displacement curve for each load cycle. Throughout the test, the dissipation of the cumulative energy by the specimens has been calculated by summing up the dissipated energy in successive load-displacement loops and is shown in Fig.8. It has been observed that all the specimens made from fiber-reinforced concrete have higher cumulative energy dissipation capacity than the CS specimen which has been from normal concrete without adding any fibers. In all the HFRC specimens, the improvement in energy-dissipating capacity has been observed due to the inherent property of enhanced ductility. The HFRC2 beam-column joint specimen has a maximum dissipation of energy which is found to be $11186.8 \mathrm{kN}-\mathrm{mm}$. The HFRC2 specimen has also been found with a high value of ultimate loading carrying capacity of $12.63 \mathrm{kN}$. 


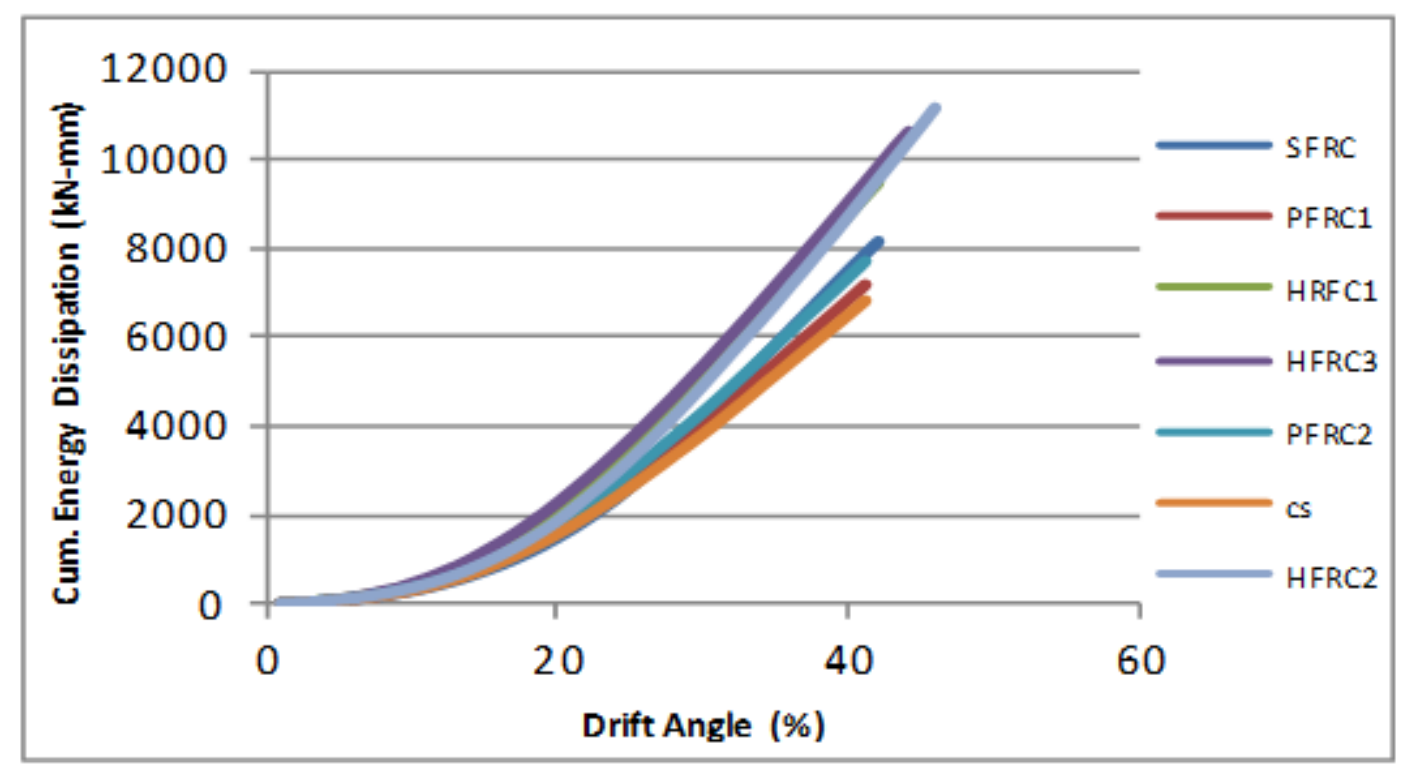

Figure 8. Comparison of cumulative energy vs. drift angle

\subsection{Degradation of Stiffness}

Degradation in the stiffness at the joint of $\mathrm{BC}$ specimens has been observed under the influence of repeated cyclic load. By estimating the secant stiffness which is an indicator of degradation of stiffness, the amount of degradation of stiffness in the BC specimens can be ascertained. The trend for the degradation of stiffness for the BC joint specimens is shown in Fig. 9. The lowest value of initial stiffness and also a rapid rate of reduction in the secant stiffness have been observed in the CS specimen. The degradation of stiffness trend in the PFRC specimens was in line with that of CS specimens. Generally, polypropylene fibers have a lower modulus of elasticity. Probably this could not contribute much to the stiffness of PFRC specimens. A decrease in the rate of degradation of stiffness can be seen after the introduction of steel fibers in comparison to the polypropylene fibers. A significant improvement in the initial secant value has been observed after the introduction of hybrid fibers in the specimens and a consistent degradation in the stiffness has been observed till failure. Hybrid fibers played a vital role which in combination has great capabilities to arrest the cracks at both micro and macro level. Micro crack develops in the specimens with the increase in the number of load cycles which can be controlled by the polypropylene fibers due to its presence in large numbers. Macro cracks as well as the widening of cracks can be controlled by steel fibers due to its special material properties. This, in turn, will be very much helpful in arresting the further propagation of cracks and as result will enhance the energy absorption capacity of the specimens. It is evident from the result that with the increase in the value of displacement, there is a decrease in the value of stiffness for all the specimens of $\mathrm{BC}$ joint with or without fibers. A sharp decrease in the stiffness can be observed at the initial stage and a gradual decrease in the stiffness can be seen at a later stage. From the results, it is seen that specimen HFRC2 can perform better as it exhibits the highest stiffness up to failure load. 


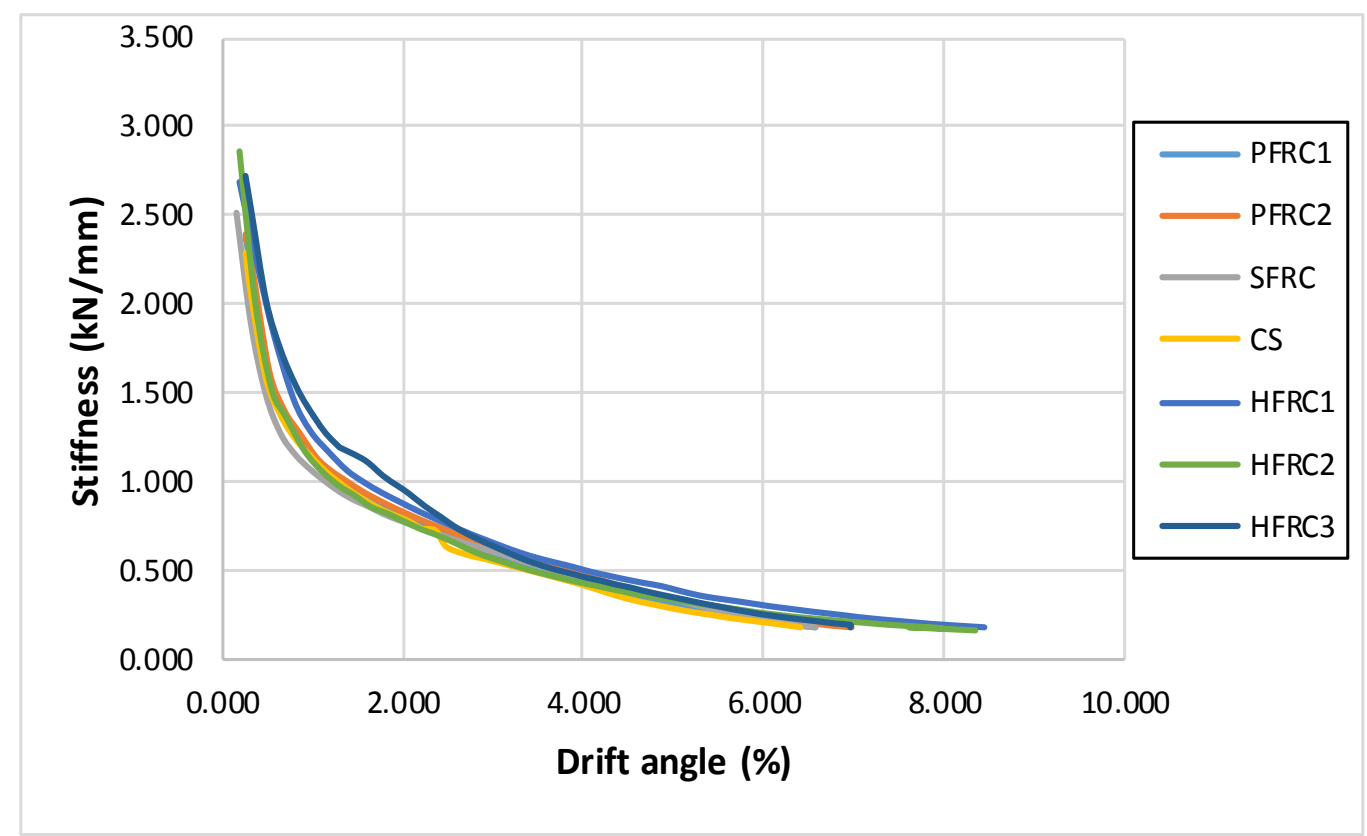

Figure-9. Comparison of stiffness vs. drift angle

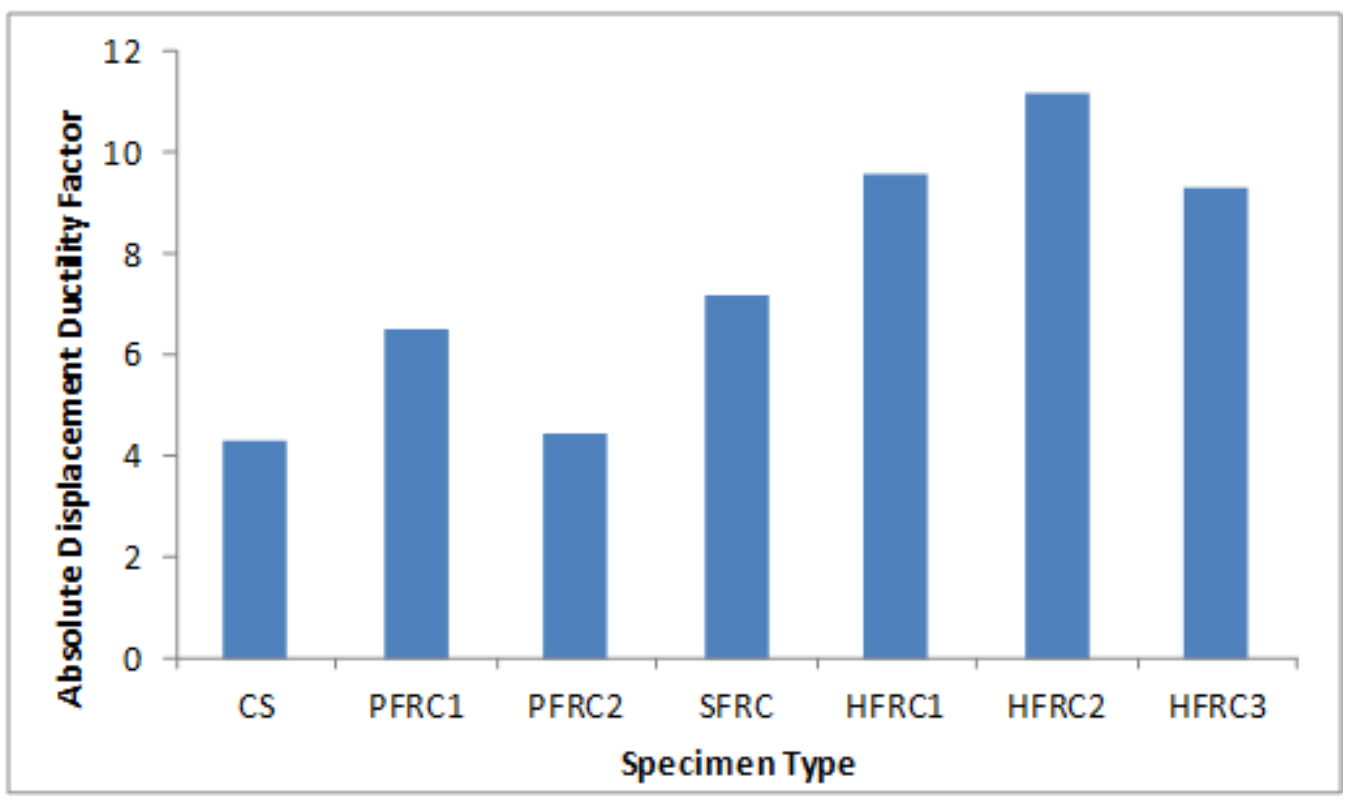

Figure 10. Absolute displacement graph

\section{Conclusions}

Performance of the beam-column joint with hybrid and non-hybrid fiber reinforced concrete specimens using various types of fibers under reversed cyclic loading are examined in the present case. The performance of these specimens was observed in terms of hysteresis behavior, load-deflection characteristics, stiffness degradation, dissipation of energy, etc. The experimental results dictate the use of hybrid fibers for the improvement of strength and ductility of beam-column joints considerably. The output of the experiments conducted for different specimens lead to the following conclusions:

1. The first visible crack has been observed in the control specimen CS at an applied displacement of $1 \mathrm{~mm}$ and in some of the fiber-reinforced specimens; the first visible crack appeared on the application of 2 $\mathrm{mm}$ displacement.

2. It has been noticed from the experimental results that the specimens made by the addition of fibers experienced ultimate load in comparison to the control specimen. The specimen HFRC2 yields a remarkable increase in first-crack strength and ultimate strength, as well as improved ductility and 
energy-dissipation capacity compared to other tested specimens.

3. For the specimens with fibers, stiffness has decreased at a similar rate with the increment in applied displacement. And the stiffness was more compared to the control specimen.

4. All the specimens with fiber exhibit higher cumulative energy dissipation than that of the CS specimen which was made without fibers. The maximum energy dissipation can be seen in the HFRC2 BC joint specimen with $0.75 \%$ steel fiber and $0.25 \%$ polypropylene fiber.

5. The capacity of energy absorption and displacement ductility has been improved by 1.63 times and 2.58 times, respectively, for HFRC2 specimen in comparison to CS specimen.

6. The above methodology may be implemented in general construction practices which may be beneficial for the construction industry. The congestion of reinforcement in conventional concrete in beam-column joint is a real-life problem faced in the construction industry and the same may be avoided by the introduction of fiber in the ordinary concrete used in construction.

\section{REFERENCES}

[1] KR Muthuswamy, GS Thirugnanam, "Structural behaviour of hybrid fiber reinforced concrete exterior Beam-Column joint subjected to cyclic loading", Journal of civil and structural engineering, Vol.4, No.3, pp.262-273, 2014.

[2] B Li, ES Lam, B Wu and Y Wang, "Experimental investigation on reinforced concrete interior beam-column joints rehabilitated by fibrocement jackets", Journal of Engineering Structures, Vol.56, pp.896-909, 2013.

[3] SM Kularni, YD Patil, "A Novel Reinforcement Pattern for Exterior Reinforced Concrete Beam-Column Joint ", Proceedings of 3rd Nirma University International Conference on Engineering, Vol.51, pp.184-193, (NUICONE 2012).

[4] R Kadarningsih, I Satyarno, Muslikh, A Triwiyono, "Proposals of beam column joint reinforcement in reinforced concrete moment resisting frame : A literature review study", Proceedings of $2^{\text {nd }}$ International Conference on Sustainable Civil Engineering Structures and Construction Materials, Vol.95, pp.158-171, 2014.

[5] MA Al-Ostaa, MN Isa, MH Baluch and MK Rahman, "Flexural behavior of reinforced concrete beams strengthened with ultra-high performance fiber reinforced concrete", Journal of Construction and Building Materials, vol.134, pp.279-296, 2017.

[6] S Chidambaram, P Agarwal, "Seismic behavior of hybrid fiber reinforced cementitious composite beam-column joints", Journal of Materials and Design, Vol.86, pp.771-781, 2015.
[7] V Vairagade, $\mathrm{K}$ Kene, "Experimental Investigation on Hybrid Fiber Reinforced Concrete", Journal of Engineering Research and Applications, Vol.2, No.3, pp.1037-1041, 2012.

[8] OF Kharoob, MF Ghazy, NM Yossef, "Behavior of beam-high performance fiber reinforced CFST column joints", Journal of Thin-Walled Structures, Vol.113, pp.217-227, 2017.

[9] M Cooa, T Pheeraphan, "Effect of sand, fly ash and limestone powder on preplaced aggregate concrete mechanical properties and reinforced beam shear capacity", Journal of Construction and Building Materials, Vol.120, pp.581-592, 2016.

[10] C Röhm, B Novák, S Sasmal, R Karusala, V Srinivas, "Behaviour of fiber reinforced beam-column sub-assemblages under reversed cyclic loading", Journal of Construction and Building Materials, Vol.36, pp.319-329, 2012.

[11] G Kotsovou, H Mouzakis, "Exterior RC beam-column joints: New design approach", Journal of Engineering Structures, Vol.41, pp.307-319, (2012).

[12] C Qian, P Stroeven, "Fracture Properties of Concrete Reinforced with steel -polypropylene hybrid fibers", Cement and Concrete Composites, Vol. 22, pp. 343-35, 2000 .

[13] R Realfonzo, Annalisa Napoli and Joaquín Guillermo Ruiz Pinilla, "Cyclic behavior of RC beam-column joints strengthened with FRP systems", Journal of Construction and Building Materials, Vol.54, pp. 282-297, 2014.

[14] WT Lee, YJ Chiou, MH Shih, "Reinforced concrete beam-column joint strengthened with carbon fiber reinforced polymer", Journal of Composite Structures, Vol.92, pp.48-60, 2010.

[15] HA Hasan, N Sheikh, M Hadi, "Performance evaluation of high strength concrete and steel fiber high strength concrete columns reinforced with GFRP bars and helices", Journal of Construction and Building Materials, Vol.134, pp.297-310, 2017.

[16] P Perumal and B Thanukumari, "Seismic performance of hybrid fiber reinforced Beam - Column joint", Journal of civil and structural engineering, Vol.1, No.4, pp.749-779, 2010.

[17] C Qian, P Stroeven," Fracture Properties of Concrete Reinforced with steel -polypropylene hybrid fibers ", Cement and Concrete Composites, Vol. 22, pp. 343-351, 2000.

[18] K Johnson, G Hemalatha "Analysis and experimental study on strength and behaviour of exterior beam-column joints with diagonal cross bracing bars and steel fibers for improving the joint ductility", Int. J. Civil Eng. Technol., 8 (1) (2017), pp. 170-188.

[19] S Hakuto, R Park, H Tanaka "Seismic load tests on interior and exterior beam-column joints with substandard reinforcing details", ACI Struct J, 97 (1) (2000), pp. 11-25.

[20] AY Ali, AA Al-Rammahi, "Flexural behaviour of hybrid -reinforced concrete exterior beam-column joints under static and cyclic loads", Fibers, (2019) pp. 7-94. 
[21] K. Mohanapriya, SSA Rahman, "Analytical study on the behaviour of beam column joint using basalt fiber under cyclic loading" Int. J. Civ. Eng. Technl. 8 (4) (2014) $1580-1589$.

[22] M M. Eldeeb, KG Metwally, AY Aki, et al., "Investigating the efficiency of using the carbon fiber polymer on beam column connection", Beni-Suef Univ. J. Basic Appl. Sci. (2015) 31-44.

[23] A. Shadrach Jeya Sekaran, K. Palani Kumar, K. Pichandi, "Evadecluation on mechanical properties of woven aloevera and sisal fiber hybrid reinforced epoxy composites", Indian Acad. Sci. , Bull. Mater. Sci. 38 (5) (2015) 1183-1193.

[24] N Attari, YS Youcef, S Amziane, "Seismic performance of reinforced concrete beam-column joint strengthening by frp sheets", Structures, 20, pp. 353-364, 2019.

[25] MH Saghafi, A Golafshar, MS Zareian, M Kashani, “The effect of high-performance fiber-reinforced cementitious composites on the lateral behavior of reinforced concrete frames without seismic details", Structures, 26, pp. 801-813, 2020.

[26] Rao Poleswara Kovela, Balaji K.V.G.D, Phanindranath T. S. D, Kumar B. Santhosh, "Effect of Additional Reinforcement Length in Beams on Base-Shear Capacity in Performance-based Design of Low-Rise Buildings," Civil Engineering and Architecture, Vol. 9, No. 1, pp. 9 - 22, 2021. DOI: $10.13189 /$ cea.2021.090102.

[27] Bahrami Alireza, Mahmoudi Ali Kouhi, "Compressive Behaviour of Circular, Square, and Rectangular Concrete-Filled Steel Tube Stub Columns," Civil Engineering and Architecture Vol. 8(5), pp. 1119 - 1126. DOI: $10.13189 /$ cea.2020.080538.

[28] IS 13920: 2016 Ductile detailing of reinforced concrete structures subjected to seismic forces - Code of practice, First Revision, Bureau of Indian Standards, New Delhi. 